\title{
Genetic and Biochemical Study of Threonine-Overproducing Mutants of Saccharomyces cerevisiae
}

\author{
MARCO A. DELGADO,$\dagger$ JOSEFA GUERRERO, AND JAIME CONDE ${ }^{*}$
}

Departamento de Microbiologia, Facultad de Biologia, University of Seville, Seville, Spain

Received 24 June 1981/Accepted 1 March 1982

\begin{abstract}
Three threonine-overproducing mutants were obtained as prototrophic revertants of a hom 3 mutant strain of Saccharomyces cerevisiae. The gene HOM3 codes for aspartokinase (aspartate kinase; EC 2.7.2.4), the first enzyme of the threonine-methionine biosynthetic route, which is subjected to feedback inhibition by threonine. Enzymatic studies indicated that aspartokinase from the revertants has lost the feedback inhibition, resulting in overproduction of threonine. These revertants also bore one or two additional mutations, named texl-1 and tex2-1, which alone or jointly made possible the excretion of the threonine accumulated. The effect of these two genes on excretion is potentiated by excess inositol in the medium.
\end{abstract}

Many biosynthetic routes are feedback regulated at the level of their first enzyme. Mutants overproducing the end product of these routes can be obtained by eliminating the feedback regulation. One method widely employed involves the selection of mutants resistant to toxic analogs of the desired end product (5). Another method starts with a nonfunctional mutant from which functional revertants are selected. In some cases, this second mutation simultaneously inactivates the feedback-sensitive site and restores function, originating a deregulated enzyme $(5,7,23)$.

Aspartokinase (aspartate kinase; EC 2.7.2.4) is the first enzyme of the methionine-threonine biosynthesis route in Saccharomyces cerevisiae. It plays a key role in the regulation of the biosynthesis of homoserine, the common intermediate in this branched pathway, and is feedback inhibited by homoserine and threonine.

To obtain mutants overproducing threonine, we started with an aspartokinase-defective strain. Revertants prototrophic for homoserine were selected. Some of these overproduced and excreted threonine.

The genetic and biochemical characterization of these mutants showed that the overproduction of threonine was caused by the insensitivity to feedback inhibition of aspartokinase. The excretion of threonine was independent of the overproduction and depended on two genes of unidentified function.

† Present address: Ingenieria Quimica Tarragona, Tarragona, Spain.

‡ Present address: La Cruz del Campo S.A., Seville, Spain.

\section{MATERIALS AND METHODS}

Strains. The yeast strains used are listed in Table 1.

Media. Complete medium contained $1 \%$ yeast extract, $2 \%$ peptone (both from Difco), and $2 \%$ glucose. Synthetic minimal medium contained the same components as $0.67 \%$ yeast nitrogen base (Difco) plus $2 \%$ glucose, but without inositol. For testing and measuring excretion, inositol $(10 \mathrm{mg} /$ liter $)$ was added. For determining auxotrophic requirements, minimal medium was supplemented with $60 \mathrm{mg}$ of each requirement per liter. Presporulation medium contained $0.8 \%$ yeast extract, $0.3 \%$ peptone, and $10 \%$ glucose. Sporulation medium contained $0.1 \%$ yeast extract, $1 \%$ potassium acetate, and $0.05 \%$ glucose. When necessary, $2 \%$ agar (Difco) was added to all media.

NTG mutagenesis. An overnight culture of $S$. cerevisiae was harvested and suspended in $5 \mathrm{ml}$ of $0.1 \mathrm{M}$ Tris-maleic buffer (pH 5.5). $N$-Methyl- $N^{\prime}$-nitro- $N$-nitrosoguanidine (NTG) was added to a final concentration of $0.1 \mathrm{mg} / \mathrm{ml}$. After incubation in the dark at $28^{\circ} \mathrm{C}$ for $15 \mathrm{~min}$, the culture was centrifuged and washed twice with $0.1 \mathrm{M}$ phosphate buffer $(\mathrm{pH}$ 7.3). The survival rate was about $10 \%$.

EMS mutagenesis. A culture in stationary phase was collected and suspended in $10 \mathrm{ml}$ of $0.1 \mathrm{M}$ potassium phosphate buffer ( $\mathrm{pH} \mathrm{8.0)}$. Ethyl methane sulfonate (EMS) was added to a final concentration of $3 \%$, and the culture was stirred vigorously. This suspension was incubated at $28^{\circ} \mathrm{C}$ for $1 \mathrm{~h}$. The cells were washed once with $10 \%$ sodium thiosulfate and twice with sterile water. The survival rate was about $30 \%$.

Isolation of excretor mutants. The threonine-auxotrophic strain MC215 was grown in complete medium, centrifuged, and washed. One milliliter of the suspension, containing about $10^{6}$ cells, was plated on minimal medium, and the mutants to be tested for excretion were streaked on this layer. After 2 to 3 days, plates were examined for the presence of halos growing around the streaks, indicating that threonine was being excreted.

Determination of free and intracellular threonine. 
TABLE 1. Yeast strains

\begin{tabular}{|c|c|c|}
\hline Strain & Genotype & Source \\
\hline S2207A & $\begin{array}{l}\alpha \text { hom3 his6 ura3 gal2 } \\
\text { texl-1 }\end{array}$ & YGSC $^{a}$ \\
\hline JG1 & $\begin{array}{l}\alpha \text { hom }^{\text {r }} \text { his6 ura3 gal2 } \\
\text { texl-I }\end{array}$ & This paper \\
\hline JG2 & $\begin{array}{l}\alpha \text { hom }^{\mathrm{r}} \text { his6 ura3 gal2 } \\
\text { texl-I }\end{array}$ & This paper \\
\hline JG3 & $\begin{array}{l}\alpha \text { hom } 3^{\mathrm{r}} \text { his6 ura3 gal2 } \\
\text { tex1-1 tex2-1 }\end{array}$ & This paper \\
\hline JGX1-27A & a prototrophic strain & This paper \\
\hline JGX1-27B & $\alpha$ his6 ura3 ade 2 & This paper \\
\hline JGX1-27C & a his6 & This paper \\
\hline JGX1-27D & $\alpha$ ura3 ade2 & This paper \\
\hline JGX1-20B & a hom $3^{\mathrm{r}}$ ura3 texl-I & This paper \\
\hline JGX1-3A & a hom $3^{\mathrm{r}}$ ade2 texl-1 & This paper \\
\hline JGX1-21C & $\alpha$ hom3 $3^{\mathrm{r}}$ ura3 texl-1 & This paper \\
\hline JGX1-24C & a hom $3^{\mathrm{r}}$ ade2 texl-l & This paper \\
\hline MDX1-5C & a hom $3^{\mathrm{r}}$ ade 2 tex2-1 & This paper \\
\hline F6 & a ade2 & J. Conde \\
\hline MC197 & $\begin{array}{l}\text { a adel trpl ura3 his } 2 \text { arg } 4 \\
\text { metl } 4 \text { lys } 7\end{array}$ & J. Conde \\
\hline D2862D & a hisl ade2-l & J. Conde \\
\hline MC215 & $\alpha$ thrl argl & J. Conde \\
\hline $\mathrm{X} 2180-1 \mathrm{~A}$ & a Wild type & YGSC \\
\hline $\mathrm{X} 2180-1 \mathrm{D}$ & $\alpha$ Wild type & YGSC \\
\hline
\end{tabular}

${ }^{a}$ YGSC, Yeast Genetic Stock Center.

Cultures were centrifuged after $48 \mathrm{~h}$, and the supernatants were stored in the cold. To determine intracellular threonine, approximately $300 \mathrm{mg}$ of the pellet was immediately extracted with $5 \mathrm{ml}$ of boiling water for 20 min. A clear supernatant was obtained after centrifugation and filtration. Dry weight was determined in a sample of the original culture. Excreted or intracellular threonine was determined in the corresponding supernatant by the gas chromatography procedure of Roach et al. $(24,25)$ as modified by Gehrke et al. (10).

Genetic methods. Conventional procedures were used for mating the strains, diploid selection, complementation testing, and tetrad analysis (20). We labeled with $\mathrm{X}$ all of the diploid strains and their meiotic derivatives (Fig. 1). These derivatives bear another label indicating the tetrad and spore from which they arose.

Phenotypic characterization of the spores. Spore clones were replica plated to screening media according to the auxotrophic requirements involved in the cross. Excretion was tested as described above. For mating-type determination, the clones were crossed with strains X2180-1A and X2180-1B, which are two opposite mating-type test strains. The presence of zygotes was determined under the microscope.

Preparation of cell-free extracts. Cells from 1 liter of growth medium were harvested by centrifugation at the end of the logarithmic phase and washed with 100 $\mathrm{ml}$ of cold $0.02 \mathrm{M}$ potassium phosphate buffer $(\mathrm{pH}$ 6.75 ). Extracts were prepared by mixing the cells with an equal volume of glass beads $(0.2-\mathrm{mm}$ diameter) and phosphate buffer.

The mixture was vigorously stirred five times for 1 min in a Super-Mixer (Lab-Line Instruments, Inc.). After each mixing interval, the suspension was cooled for $1 \mathrm{~min}$ on ice. The resulting slurry was centrifuged for $90 \mathrm{~min}$ at $16,000 \times g$, and the supernatant obtained was used as a source of enzyme. The protein content was measured by the method of Lowry et al. (17).

Aspartokinase activity assay. Aspartokinase was assayed as described by Stadtman et al. (30).

\section{RESULTS}

Isolation of threonine excretors. Strain S2207A, an aspartokinase-deficient hom 3 mutant, was subjected to EMS or NTG mutagenesis and plated on minimal medium for the selection of homoserine-prototrophic revertants. These revertants were tested for excretion of threonine. Of 51 revertants obtained by EMS mutagenesis and 82 revertants obtained by NTG mutagenesis, 2 (JG1 and JG2) and 1 (JG3), respectively, proved to be threonine excretors.

Phenotypic characterization of strains JG1, JG2, and JG3. The threonine content in the medium and in the intracellular pool was determined for three excretor mutants. JG1 and JG2 were similar in overproduction and excretion; both levels were lower in these strains than in JG3 (Table 2).

Table 2 also shows the stimulating role of inositol in the excretion of threonine. Cells grown in the presence of inositol had a lower intracellular level and excreted more threonine than did cells grown without it. The action of inositol on threonine excretion is optimal at inositol concentrations of 10 to $20 \mathrm{mg} / \mathrm{liter}$. Moreover, in the absence of inositol strains JG1, JG2, and JG3 all failed to support the growth of the threonine-auxotrophic strain MC215. The presence or absence of inositol in the medium did not affect the growth yield of JG1, JG2, or JG3 (data not shown).

Genetic characterization of JG1, JG2, and JG3. Strains JG1 and JG2 were crossed with strain F6 (crosses JGX1 and JGX2). Strain JG3 was crossed with strain D2862D (cross MDX1). All of the diploids so formed were nonexcretors, suggesting that at least some of the mutations which determine the excretor phenotype in these three strains are recessive.

The diploids described above were allowed to sporulate and dissected by tetrad analysis. The segregations of JGX1 and JGX2 fit closely the hypothesis of a digenic genotype for excretion (Table 3). The segregation of the diploid MDX1 is more complex and will be considered later.

Since the diploid JGX3 (a cross between JG2 and JGX1-24C, an excretor meiotic derivative of the cross JGX1) is an excretor and JG1 and JG2 were isolated in the same experiment, we suppose that both JG1 and JG2 are allelic mutants. For this reason, only JG1 will be studied further.

Genetic analysis of JG1. An unexpected result was obtained when strain JGX1-24C was crossed with S2207A (cross JGX6), the strain 


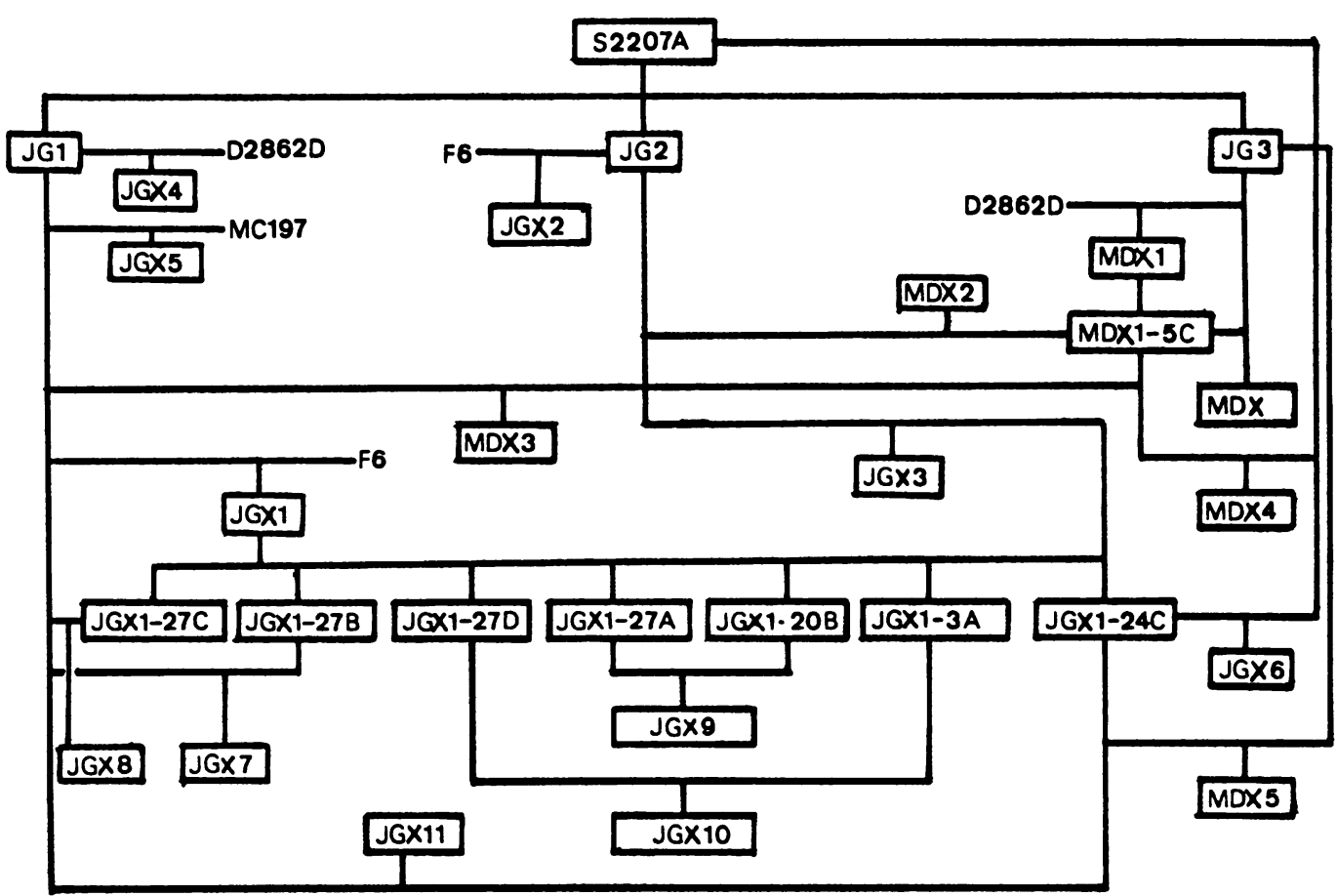

FIG. 1. Genetic crosses reported in this work.

from which the mutant JG1 was obtained. The diploid JGX6 was an excretor, and its meiotic segregation for excretion was clearly monogenic. This suggests that one of the two genes responsible for excretion in the mutant JG1 was already present in its parental strain (S2207A) and also identifies it as being different from the reversion in gene $H O M 3$.

Tetrad 27 from the cross JGX1 gave a 0 excretor:4-nonexcretor spores segregation. According to the digenic hypothesis, two of the spores harbor one of the mutations responsible for excretion and two spores harbor the other

TABLE 2. Accumulated (pool) and excreted (medium) threonine in 48-h-old cultures of JG1, JG2, and JG3 strains

\begin{tabular}{|c|c|c|c|c|}
\hline \multirow{3}{*}{ Strain } & \multicolumn{4}{|c|}{ Threonine (mg/g, dry wt) in culture: } \\
\hline & \multicolumn{2}{|c|}{ Without inositol } & \multicolumn{2}{|c|}{ With inositol } \\
\hline & Pool & Medium & Pool & Medium \\
\hline JG1 & 20.7 & 8.0 & 14.2 & 11.1 \\
\hline JG2 & 17.0 & 4.0 & 16.3 & 10.0 \\
\hline JG3 & 36.0 & 19.5 & 9.2 & 34.7 \\
\hline $\mathrm{F}^{a}{ }^{a}$ & 1.6 & $\mathrm{ND}^{b}$ & 1.3 & ND \\
\hline
\end{tabular}

${ }^{a}$ F6 was included as a control.

$b$ ND, Not detected. mutation. The four spores were crossed with JG1 or its excretor meiotic derivatives, JGX120B and JGX1-3A. The resultant diploids were nonexcretors. In these four cases the segregations for excretion were monogenic. These results clearly confirm that in the JG1 mutant there are two independent mutations jointly responsible for the excretor phenotype.

Tetrad 32 from the cross JGX1 gave a 1excretor:3-nonexcretor segregation. It is therefore a tetratype tetrad, holding the four possible combinations of mutant and wild-type alleles of the two genes responsible for excretion.

TABLE 3. Meiotic segregation of the excretor characteristics present in some of the crosses described in this work

\begin{tabular}{l|c|c|c|c|c|c}
\hline \multirow{2}{*}{ Cross } & \multirow{2}{*}{$\begin{array}{c}\text { No. of } \\
\text { tetrads } \\
\text { ana- } \\
\text { lyzed }\end{array}$} & \multicolumn{5}{|c}{ Segregation into tetrad type: } \\
\cline { 3 - 7 } & 32 & 3 & 23 & 6 & 0 & 0 \\
\hline JGX1 & 32 & 3 & 15 & 1 & 0 & 0 \\
JGX2 & 19 & 3 & 6 & 13 & 0 & 0 \\
MDX1 & 19 & 0 & & & & \\
MDX3 & 27 & 0 & 0 & 8 & 12 & 7 \\
MDX4 & 18 & 1 & 3 & 14 & 0 & 0 \\
\hline
\end{tabular}

${ }^{a}$ E, Excretor spore; NE, nonexcretor spore. 
The four spores were grown on minimal medium to stationary phase ( $48 \mathrm{~h}$ ), and intracellular and excreted threonine was analyzed. The two genes which intervene in excretion have different functions (Table 4). One of them determines the overproduction of threonine, and it is probably an allele of gene $\mathrm{HOM}_{3}$, which we have called hom $3^{\mathrm{r}}$, which codes for a functional but feedback-insensitive aspartokinase. The other gene is related to the excretion of accumulated threonine into the medium. We called it TEXI, and texl-l is the recessive mutant allele responsible for excretion and present in the original strain S2207A.

To obtain genetic evidence that the mutation responsible for overproduction is the allele hom $3^{\mathrm{r}}$, we crossed strains JG1 and JG3 with D2862D, a his I mutant (crosses JGX4 and MDX1).

Since gene HOM3 is located adjacent to gene HISl (4 centimorgans), the meiotic segregation expected for the hypothesis in which the hom $3^{\mathrm{r}}$ allele acts on excretion must show a high percentage $(96 \%)$ of spores that are simultaneously excretors and prototrophic. The results confirmed this hypothesis. All 56 excretor spores derived from of JGX4 carried the HISI marker. Of 32 excretor spores derived from of MDX1, 28 carried the HISI marker and 4 carried hisI.

Using the same experimental procedure, we showed (in cross JGX5) that threonine overproduction was not modulated by the enzyme homoserine kinase (EC 2.7.1.39), which regulates the shift from homoserine to threonine (data not shown).

Analysis of aspartokinase activity. Definitive proof for the postulated mechanism of threonine overproduction in the JG1 and JG3 strains would be to show in vitro that their aspartokinases are insensitive to feedback inhibition by threonine. The aspartokinase activities of JG1 and JG3 were not sensitive to inhibition by threonine, whereas the aspartokinase activity of the control strain F6 showed a normal, strong sensitivity (Table 5). Moreover, the diploid JGX1 had a semidominant behavior in accord with the nature of the deregulation present in JG1.

To obtain biochemical confirmation for the

TABLE 4. Threonine pooled and excreted by the spores of one tetratype tetrad from cross JGX1

\begin{tabular}{|c|c|c|c|}
\hline \multirow{2}{*}{ Spore } & \multicolumn{2}{|c|}{$\begin{array}{l}\text { Threonine (mg/g, dry } \\
\text { wt): }\end{array}$} & \multirow{2}{*}{$\begin{array}{l}\text { Assigned } \\
\text { genotype }\end{array}$} \\
\hline & Pooled & $\overline{\text { Excreted }}$ & \\
\hline JGX1-32A & 0.5 & 2.9 & HOM3 texl-1 \\
\hline JGX1-32B & 5.5 & 43.6 & hom $3^{\mathrm{r}}$ texl-1 \\
\hline JGX1-32C & $\operatorname{tr}$ & $\operatorname{tr}$ & HOM3 TEXI \\
\hline JGX1-32D & 16.9 & 3.2 & hom $3^{\mathrm{r}} T E X 1$ \\
\hline
\end{tabular}

TABLE 5. Inhibition by threonine of aspartokinase activity in overproducer and non-overproducer strains

\begin{tabular}{lcccc}
\hline & \multicolumn{4}{c}{$\begin{array}{c}\text { Aspartokinase activity (\%) } \\
\text { concn of: }\end{array}$} \\
\cline { 2 - 5 } Strain & $0 \mathrm{mM}$ & $1 \mathrm{mM}$ & $5 \mathrm{mM}$ & $10 \mathrm{mM}$ \\
\hline JG1 & 100 & 100 & 95.1 & 95.1 \\
JG3 & 100 & 100 & 94 & 91.6 \\
JGX1 & 100 & 97.6 & 73.4 & 45.7 \\
F6 & 100 & 100 & 49 & 4.1 \\
\hline
\end{tabular}

${ }^{a}$ Aspartokinase activity is expressed as the percentage of its activity when assayed in the absence of threonine.

genotypes assigned to tetrad 32 from JGX1 (Table 4), we measured aspartokinase activity in the presence and absence of threonine in the four spores of this tetrad. Spores JGX1-32A and JGX1-32C had a threonine-sensitive aspartokinase, as had strain F6 (Table 6), whereas JGX1$32 \mathrm{~A}$ showed a release of threonine into the medium, in accord with the genotype texl-l proposed for it (Table 4). Spores JGX1-32B and JGX1-32D had a threonine-insensitive aspartokinase, as had strain JG1. JGX1-32D did not show excretion but had a higher accumulation of threonine than did JGX1-32B, also in accord with the genotype $T E X I$ proposed for it.

Genetic analysis of strain JG3. MDX1 (Table 3) showed an abnormal meiotic segregation for excretion, with an excess of parental ditype tetrads. To explain this fact, two different hypotheses can be postulated. Both assume the existence of another gene, TEX2, whose allele tex $2-1$ codes for the excretion of overproduced threonine as does texl-1.

The first hypothesis is that the genotype of strain JG3 is hom $3^{\mathrm{r}}$ tex $2-1$; then tex2-1 would be linked to gene HOM3. However, in contradiction to this hypothesis, the diploid MDX5, a cross between JGX1-24C and JG3, was an excretor.

The second hypothesis is that strain JG3 is a double texl-1 tex2-1 mutant and that either one of the tex mutations can determine an excretor phenotype. By this hypothesis, the expected segregation for excretion in MDX1 would be similar to that obtained experimentally.

To test this second hypothesis, we chose the excretor spore MDX1-5C, obtained from a parental ditype tetrad, and crossed it with strains JG1, JG2, JG3, and S2207A. All of the diploids except MDX6 (cross between MDX1-5C and JG3) were found to be nonexcretors. This and the fact that the diploid MDX5 was an excretor support the validity of the second hypothesis.

On these grounds, we predicted that the genotypes of strains JG3 and MDX1-5C were, respectively, hom $3^{r}$ texl-1 tex2-1 and hom $3^{r}$ tex2-1. To 
TABLE 6. Effect of threonine on aspartokinase activity in the four spores of tetrad 32 from cross JGX1

\begin{tabular}{lllr}
\hline \multirow{2}{*}{ Strain $^{a}$} & $\begin{array}{l}\text { Aspartokinase activi- } \\
\text { ty }\left(\mathrm{mM} \mathrm{g}^{-1} \mathrm{~min}^{-1}\right) \text { at } \\
\text { a threonine concn of: }\end{array}$ & $\begin{array}{c}\text { Inhibition } \\
(\%)\end{array}$ \\
\cline { 2 - 4 } & $\mathbf{0 ~ m M}$ & $10 \mathrm{mM}$ & \\
\hline JGX1-32A & 1.27 & 0.04 & 97 \\
JGX1-32B & 0.83 & 0.83 & 0 \\
JGX1-32C & 1.26 & 0.06 & 96 \\
JGX1-32D & 0.88 & 0.87 & 2 \\
F6 & 1.2 & 0.02 & 98 \\
JG1 & 0.85 & 0.84 & 1 \\
\hline
\end{tabular}

${ }^{a}$ F6 and JG1 were included as regulated and nonregulated control strains, respectively.

prove this prediction, the meiotic segregations of the crosses of strain MDX1-5C with the parental strain S2207A and MDX1-5C with the JG1 strain (crosses MDX4 and MDX3) were examined. The segregations obtained fit closely to the above predictions (Table 3). All of these data allowed us definitively to assign the genotype hom $3^{r}$ texl-1 tex2-1 to strain JG3.

\section{DISCUSSION}

We isolated and characterized three threonine-overproducing mutants. They had an intracellular threonine content at least 20 times greater than that reported by Watson (32) or found by us in the wild-type strain F6.

Mutants able to excrete amino acids have been previously isolated from $S$. cerevisiae (11, $18,19,22,29)$ and other yeasts $(8,21,31)$. In all cases in which the genetics were studied, excretion was shown to be a consequence of overproduction, and both characteristics have the same genotypic origin.

Gaillardin et al. (9) described a lysine excretor mutant of $S$. cerevisiae which bears two mutations. One, called $m g 5$, codes for insensitivity to homocitrate synthase and overproduction of lysine. Another mutation, called lex, allows the excretion of lysine into the medium.

In the mutants described here, we could clearly distinguish between the overproducer and excretor phenotypes. Both characteristics are determined by different, unlinked genes.

Revertant alleles of gene $H O M 3$ code for active but feedback-insensitive aspartokinases and cause overproduction of threonine. The aspartokinase of the diploid JGX1 showed an intermediate level of inhibition in accord with its heteroallelic nature.

We did not observe overproduction of either homoserine or methionine. This indicates that the control of homoserine kinase by threonine $(26,28)$ was very weak in our strains. The work of Robichon-Szulmajster and Cherest (27) and Cherest et al. $(3,4)$ showed the strong control by $S$-adenosylmethionine and methionine on homoserine $O$-transacetylase (homoserine acetyltransferase; EC 2.3.1.31), which inhibits the deviation from homoserine to methionine.

Two genes affecting excretion have been described. We have called them TEX genes, for threonine excretion. They are unlinked and probably are similar in function. At least one of them, represented by its allele texl-1, is ab!e to cause a small but detectable excretion of threonine even when placed in a wild-type, feedbackregulated genetic background.

Grenson (12) described mutants of $S$. cerevisiae which are able to excrete arginine or other amino acids. These mutants show depressed activity of the specific permease for the excreted amino acid and an inactive general amino acid permease. Bekerich et al. (2) obtained mutants of Saccharomycopsis lipolytica which were impaired in the active transport of lysine. Some of these mutants were excretors of lysine. These authors found that at least four genes are implied in lysine uptake. Halsall (13) found mutants of Escherichia coli that were defective in the lysine transport system and also excretors of lysine.

We suggest that the TEXI and TEX2 genes may code, totally or partially, for a threoninespecific permease, although this enzyme has not been described in $S$. cerevisiae. This matter is now under study.

We also observed the effect of inositol on the excretion of threonine. Results from this laboratory showed that it had a similar effect on the excretion of lysine but not of methionine in $S$. cerevisiae (unpublished data). The role of inositol and the effects of its absence on the metabolism of lipids and carbohydrates $(1,14-16)$ in yeasts are well documented.

An excess of inositol in the growth medium may alter the proportion of distinct types of lipids at the membrane, aiding in an unknown way the excretion of some amino acids. This situation would be similar to the role of biotine in the excretion of glutamic acid by coryneform bacteria (6).

\section{ACKNOWLEDGMENT}

We thank J. M. Gancedo and C. Gancedo for their critical reading of this manuscript.

\section{LITERATURE CITED}

1. Becker, G., and R. L. Lester. 1977. Changes in phospholipids of Saccharomyces cerevisiae associated with inositol-less death. J. Biol. Chem. 252:8684-8691.

2. Beckerich, J. M., M. Lambert, and H. Heslot. 1979. Genetic control of lysine permease in Saccharomycopsis lipolytica. Arch. Microbiol. 122:201-205.

3. Cherest, H., F. Eichler, and H. de Robichon-Szulmajster. 1969. Genetic and regulatory aspects of methionine bio- 
synthesis in Saccharomyces cerevisiae. J. Bacteriol. 97:328-336.

4. Cherest, H., Y. Surdin-Kerjan, and H. de RobichonSzulmajster. 1971. Methionine-mediated repression in Saccharomyces cerevisiae: a pleiotropic regulatory system involving methionyl transfer ribonucleic acid and the product of gene eth2. J. Bacteriol. 106:758-772.

5. Demain A. L. 1972. Cellular and environmental factors affecting the synthesis and excretion of metabolites. J. Appl. Chem. Biotechnol. 22:345-362.

6. Demain, A. L., and J. Birnbaum. 1968. Alteration of permeability for the release of metabolites from the microbial cell. Curr. Top. Microbiol. 46:1-25.

7. Demain, A. L., M. Jackson, R. A. Vitali, D. Hendlin, and T. A. Jacob. 1966. Production of guanosine- 5 '-monophosphate and inosine-5'-monophosphate by fermentation. Appl. Microbiol. 14:821-825.

8. Gaillardin, C., and H. Heslot. 1979. Evidence for mutations in the structural gene for homocitrate synthase in Saccharomycopsis lipolvtica. Mol. Gen. Genet. 172:185192.

9. Gaillardin, C. M., G. Sylvestre, and H. Heslot. 1975. Studies on an unstable phenotype induced by UV irradiation. The lysine excreting (lex ${ }^{-}$) phenotype of the yeast Saccharomycopsis lipolytica. Arch. Microbiol. 104:89-94.

10. Gehrke, C. W., R. W. Zumwalt, and K. Kuo. 1971. Quantitative amino acid analysis by gas-liquid chromatography. J. Agric. Food Chem. 19:605-618

11. Gray, G. S., and J. K. Bhattacharjee. 1976. Biosynthesis of lysine in Saccharomyces cerevisiae: regulation of homocitrate synthase in analogue-resistant mutants. J. Gen. Microbiol. 97:117-120.

12. Grenson, M. 1973. Specificity and regulation of the uptake and retention of amino acids and pyrimidines in yeast, $p$. 179-183. In Z. Vanek, Z. Hostálek, and J. Cudlín (ed.), Genetics of industrial microorganisms, vol. 2. Elsevier/ North-Holland Publishing Co., Amsterdam.

13. Halsall, D. M. 1977. Overproduction of lysine by mutant strains of Escherichia coli with defective lysine transport systems. Biochem. Genet. 13:109-124.

14. Hanson, B. A., and R. L. Lester. 1980. Effects of inositol starvation on phospholipid and glycan syntheses in Saccharomyces cerevisiae. J. Bacteriol. 142:79-89.

15. Hayashi, E., R. Hasegawa, and T. Tomita. 1976. Accumulation of neutral lipids in Saccharomyces carlsbergensis by myo-inositol deficiency and its mechanism. J. Biol. Chem. 251:5759-5769.

16. Henry, S. A., K. D. Atkinson, A. I. Kolat, and M. R. Culbertson. 1977. Growth and metabolism of inositolstarved Saccharomyces cerevisiae. J. Bacteriol. 130:472484.

17. Lowry, O. H., N. J. Rosebrough, A. L. Farr, and R. J. Randall. 1951. Protein measurement with the Folin phenol reagent. J. Biol. Chem. 193:265-275.

18. Masselot, H., and H. de Robichon-Szulmajster. 1974. Methionine biosynthesis in Saccharomvces cerevisiae: mutations at the regulatory locus eth2. I. Genetic data. Mol.
Gen. Genet. 129:339-348.

19. Masselot, H., and H. de Robichon-Szulmajster. 1974. Methionine biosynthesis in Saccharomyces cerevisiae: mutations at the regulatory locus eth2. II. Physiological and biochemical data. Mol. Gen. Genet. 129:349-362.

20. Mortimer, R. K., and D. C. Hawthorne. 1969. Yeast genetics, p. 386-460. In A. H. Rose and J. S. Harrison (ed.), The yeasts, vol. 1. Academic Press, Inc.. New York.

21. Morzycka, E., D. Sawnor-Korszynska, A. Paszewski, J. Grabski, and K. Raczynska-Bojanowska. 1976. Methionine overproduction by Saccharomycopsis lipolytica. Appl. Environ. Microbiol. 32:125-130.

22. Rasse-Messenguy, F., and G. R. Fink. 1974. Feed-back resistant mutants of histidine biosynthesis in yeasts, $p$. 85-95. In A. M. Srb (ed.). Genes, enzymes, and populations. Plenum Publishing Corp., New York.

23. Reh, H., and H. G. Schelegel. 1969. Die Biosynthese von Isoleucin und Valin in Hidrogenomonas H16. Arch. Mikrobiol 67:110-127.

24. Roach, D., and W. C. Gerhke. 1969. Direct esterification of the protein amino acids. Gas-liquid chromatography of N-TFA n-butyl esters. J. Chromatogr. 44:269-278.

25. Roach, D., and W. C. Gehrke. 1969. The gas-liquid chromatography of amino acids. J. Chromatogr. 43:303310 .

26. Robichon-Szulmajster, H. 1967. Régulation du functionnement de deux chaines de biosynthèse chez Saccharomyces cerevisiae: thréonine-méthionine and isoleucine-valine. Bull. Soc. Chim. Biol. 49:1431-1462.

27. Robichon-Szulmajster, H., and H. Cherest. 1967. Regulation of homoserine-o-transacetylase, first step in methionine biosynthesis in Saccharomyces cerevisiae. Biochem. Biophys. Res. Commun. 28:256-262.

28. Robichon-Szulmajster, H., Y. Surdin-Kerjan, and H. Cherest. 1973. Regulatory aspects of threonine and methionine biosynthesis in Saccharomyces cerevisiae, p. 149-162. In Z. Vanek, Z. Hostálek, and J. Cudlin (ed.). Genetics of industrial microorganisms, vol. 2. Elsevier/North-Holland Publishing Co., Amsterdam.

29. Schürch, A., J. Miozzari, and R. Hütter. 1974. Regulation of tryptophan biosynthesis in Saccharomyces cerevisiae: mode of action of 5-methyl-tryptophan and 5-methyltryptophan-sensitive mutants. J. Bacteriol. 117:11311140.

30. Stadtman, E. R., G. N. Cohen, G. LeBras, and H. de Robichon-Szulmajster. 1961. Feed-back inhibition and repression of aspartokinase activity in Escherichia coli and Saccharomyces cerevisiae. J. Biol. Chem. 236:2033-2038.

31. Takenouchi, E., T. Yamamoto, D. K. Nikolova, H. Tanaka, and K. Soda. 1979. Lysine production by $S$-(aminoethyl)L-cysteine resistant mutants of Candida pelliculosa. Agric. Biol. Chem. 43:727-734.

32. Watson, T. G. 1976. Amino acid pool composition of Saccharomyces cerevisiae as a function of growth rate and amino acid nitrogen source. J. Gen. Microbiol. 96:263-268. 